\title{
The reproductive success of black rhinoceroses in the Hluhluwe-iMfolozi Park, KwaZulu-Natal, South Africa
}

\begin{tabular}{|c|c|}
\hline \multicolumn{2}{|c|}{$\begin{array}{l}\text { Authors: } \\
\text { Zoliswa N. Nhleko } \\
\text { Dan M. Parker } \\
\text { Dave J. Druce } \\
\text { Da,4 }\end{array}$} \\
\hline $\begin{array}{l}\text { Affiliations: } \\
{ }^{1} \text { Department } \\
\text { Entomology, } \\
\text { University, Sc }\end{array}$ & $\begin{array}{l}\text { foology and } \\
\text { hodes } \\
\text { th Africa }\end{array}$ \\
\hline \multicolumn{2}{|c|}{$\begin{array}{l}{ }^{2} \text { School of Biology and } \\
\text { Environmental Sciences, } \\
\text { University of Mpumalanga, } \\
\text { South Africa }\end{array}$} \\
\hline \multicolumn{2}{|c|}{$\begin{array}{l}{ }^{3} \text { Ezemvelo KZN Wildlife, } \\
\text { KwaZulu-Natal, South Africa }\end{array}$} \\
\hline \multicolumn{2}{|c|}{$\begin{array}{l}{ }^{4} \text { School of Life Sciences, } \\
\text { University of KwaZulu-Natal, } \\
\text { South Africa }\end{array}$} \\
\hline \multicolumn{2}{|c|}{$\begin{array}{l}\text { Corresponding author: } \\
\text { Dan Parker, } \\
\text { d.parker@ru.ac.za }\end{array}$} \\
\hline \multicolumn{2}{|c|}{$\begin{array}{l}\text { Dates: } \\
\text { Received: } 17 \text { Feb. } 2016 \\
\text { Accepted: } 10 \text { July } 2017 \\
\text { Published: } 15 \text { Nov. } 2017\end{array}$} \\
\hline \multicolumn{2}{|c|}{$\begin{array}{l}\text { How to cite this article: } \\
\text { Nhleko, Z.N., Parker, D.M. \& } \\
\text { Druce, D.J., 2017, 'The } \\
\text { reproductive success of black } \\
\text { rhinoceroses in the } \\
\text { Hluhluwe-iMfolozi Park, } \\
\text { KwaZulu-Natal, South Africa', } \\
\text { Koedoe 59(1), a1386. https:// } \\
\text { doi.org/10.4102/koedoe. } \\
\text { v59i1.1386 }\end{array}$} \\
\hline \multicolumn{2}{|c|}{$\begin{array}{l}\text { Copyright: } \\
\text { (C) 2017. The Authors. } \\
\text { Licensee: AOSIS. This } \\
\text { is licensed under the } \\
\text { Creative Commons } \\
\text { Attribution License. }\end{array}$} \\
\hline \multicolumn{2}{|l|}{ Read online: } \\
\hline ary & $\begin{array}{l}\text { Scan this QR } \\
\text { code with your } \\
\text { smart phone or } \\
\text { mobile device } \\
\text { to read online. }\end{array}$ \\
\hline
\end{tabular}

Black rhinoceroses (Diceros bicornis) are endangered and the southern-central sub-species (Diceros bicornis minor) is considered critically endangered. We assessed the reproductive lifehistories of black rhinoceroses in Hluhluwe-iMfolozi Park (HiP), KwaZulu-Natal, South Africa, to determine whether this historically important donor sub-population was meeting regional reproductive targets. Detailed life-history information for known individuals ( $n=79-120)$ was used to investigate reproductive parameters between 1998 and 2013. Mean age at sexual maturity was 12 years, which exceeded a target period of 7 years and 5 months. The mean inter-calving interval was 3 years and 8 months -8 months longer than the recommended 3 years. The poor population performance of the HiP black rhinoceroses could be a result of poor habitat quality, poor animal condition, females losing their first calves, predation of calves or a negative social effect of annual live-harvesting of the population. However, we believe that the estimated ecological carrying capacity of black rhinoceroses at $\mathrm{HiP}$ (a figure used to ascertain whether the population can be harvested at all) may be incorrect, leading to the poor reproductive performance. We recommend that the accuracy of the ecological carrying capacity estimate be assessed as a matter of urgency and that a moratorium be placed on the live-harvesting of individuals until the estimate has been refined.

Conservation implications: Our results provide key data which can be used to refine black rhinoceros breeding targets in South Africa and the region more broadly.

\section{Introduction}

Globally, the conservation status of the southern-central black rhinoceros (Diceros bicornis minor) is critically endangered as a result of a population decrease of approximately $80 \%$ over the last three generations (International Union for Conservation of Nature [IUCN] 2012). This decrease has come about mainly because of poaching in the 1970's and 1980's, and the recent escalation in rhinoceros poaching (IUCN 2012). South Africa is the most important range state for this subspecies of black rhinoceros and, by the end of 2010, contained 1684 individuals (IUCN 2012). The KwaZulu-Natal province, in the eastern part of South Africa, was home to approximately 480 (29\%) individuals of this sub-species in 2012 (IUCN 2012).

In 2011, the South African government produced a Biodiversity Management Plan (BMP) for the black rhinoceros (Diceros bicornis) in which two main goals were outlined. With relevance to the southern-central black rhinoceros (hereafter black rhino), these were (1) to achieve a metapopulation growth rate of at least $5 \%$ per annum and (2) to increase the population to at least 2800 individuals by the end of 2020. These targets were to be achieved through sustainable metapopulation growth by annual live-harvesting and translocating $5 \%$ of individuals from certain sub-populations to populate additional sites (Goodman 2013). The expansion programme was dependent on the intensive monitoring of all sub-populations, including assessments of annual population sizes, population growth rates, fertility rates and mortality rates (Goodman 2013).

In addition to the national BMP, there is a provincial strategy for the management of black rhino in KwaZulu-Natal (Conway \& Goodman 2013). The provincial management document describes the overall strategy for the management and recovery of the black rhino populations on state, communal and private land in KwaZulu-Natal for the period from 2013 to 2018 (Conway \& Goodman 2013). Strategic goals are to increase the number of black rhinos in the province to at least 740 individuals by the end of 2022, to achieve an average of 0.25 births per adult female per annum (between 2013 and 2022), and to achieve a growth rate of 5\% per annum over any 3-year cycle (Conway \& Goodman 2013). One of the actions required to achieve these goals is to liveharvest populations that are greater than $70 \%$ of the estimated ecological carrying capacity, at a minimum rate of $5 \%$ up to a maximum of $8 \%$ per annum over any 3 -year cycle (Conway \& Goodman 2013). 
Hluhluwe-iMfolozi Park (HiP) is located in KwaZulu-Natal and contains one of the most important black rhino populations in southern Africa (Brooks \& Adcock 1997; Emslie \& Brooks 1999). In addition, it has historically served as a donor population for Black Rhino Range Expansion Programme (BRREP) of the World Wildlife Fund (WWF) (WWF 2012). The HiP black rhino population is believed to be above $70 \%$ of the estimated ecological carrying capacity and is therefore live-harvested for translocation at a rate of $5 \%$ per annum (Clinning et al. 2009). For these translocations to be sustainable, an annual population growth rate of at least $5 \%$ is required to ensure that black rhinos do not become locally extinct (Du Toit 2006; Hrabar \& Du Toit 2005). However, there has only been one peer-reviewed assessment of the reproductive vital rates of the HiP black rhino population and the factors which could be affecting these rates (Hitchins \& Anderson 1983), and this was prior to the establishment of the BRREP and the strategy to live harvest $5 \%$ of the population annually.

Population dynamics in herbivorous mammals are governed by the differences between births, deaths, emigration and immigration (Fowler 1981). Vital rates such as the age at sexual maturity (ASM), conception rate, gestation length and inter-calving interval (ICI) all influence fecundity, growth potential and turnover or generational time (Gaillard, FestaBianchet \& Yoccoz 1998; Gaillard et al. 2000). The minimum age at first conception indicates the potential for the population to increase because the earlier the minimum ASM, the longer the lifetime productivity (Owen-Smith 1988). Thus, if females attain sexual maturity and start reproducing at an early age, the growth rate for the population could increase even if no other vital rates change. Longer ICIs reduce the number of calves born each year and therefore result in a reduction in the population growth rate. Significantly, long-lived animals (such as black rhinos) can also be heavily influenced by stochastic environmental events such as drought, flood, fire and disease (Fowler 1981; Gaillard et al. 1998, 2000; Greaver, Ferreira \& Slotow 2013; Hrabar \& Du Toit 2005).

Because the HiP black rhino population is an important population for both the KwaZulu-Natal province and the region more broadly, it is important that its vital rates are scrutinised in relation to national and provincial population growth targets. In this study, we assessed the reproductive parameters (i.e. ASM, ICI, fertility and fecundity rates) of the HiP black rhino population. We also suggest potential drivers of the measured reproductive parameters within the HiP black rhino population. We predicted that if the HiP black rhino population was above $70 \%$ of the estimated ecological carrying capacity, then the reproductive parameters of the population would not be negatively affected by annual live-harvesting.

\section{Materials and methods}

The Hluhluwe and iMfolozi Game Reserves were founded in 1895; are located 280 km north of Durban, South Africa; and are the oldest formally proclaimed protected areas in Africa (Brooks 2000; Ezemvelo KZN Wildlife 2011). The two reserves were amalgamated in 1989 to form the HiP which is $895 \mathrm{~km}^{2}$ in size (Figure 1) (Brooks 2000). The park is divided into five management sections, namely, Manzimbomvu, Nqumeni, Masinda, Mbhuzane and Makhamisa. The park covers a vast and diverse landscape, consisting mainly of steep wooded hills, grass-covered slopes and riverine woodland along the many rivers and streams in the north of the park (Brooks 2000) and more undulating; open to bush-encroached savanna woodland in the south. It is situated in the Savanna Biome, a tropical vegetation type that is characterised by woody plants and grasses (Cowling, Richardson \& Pierce 1997). HiP is managed by Ezemvelo KwaZulu-Natal Wildlife (Ezemvelo KZN Wildlife 2011), which is a provincial nature conservation and tourism organisation responsible for the conservation of biodiversity and associated activities for the province of KwaZulu-Natal (Ezemvelo KZN Wildlife 2011).

Sightings data of individually recognisable animals have been collected at HiP from the early 1980's by field staff, scientists and students working within HiP (Clinning et al. 2009). For our assessment, we used individual black rhino sightings data from 1998 to 2013. Individual black rhinos were identified by unique patterns of notches cut into their ears during marking operations, usually whilst the calves were still with their mothers, and as part of routine black rhino management operations in the park.

Population estimates were a total of all recognisable animals; animals known by association; and known, clean animals

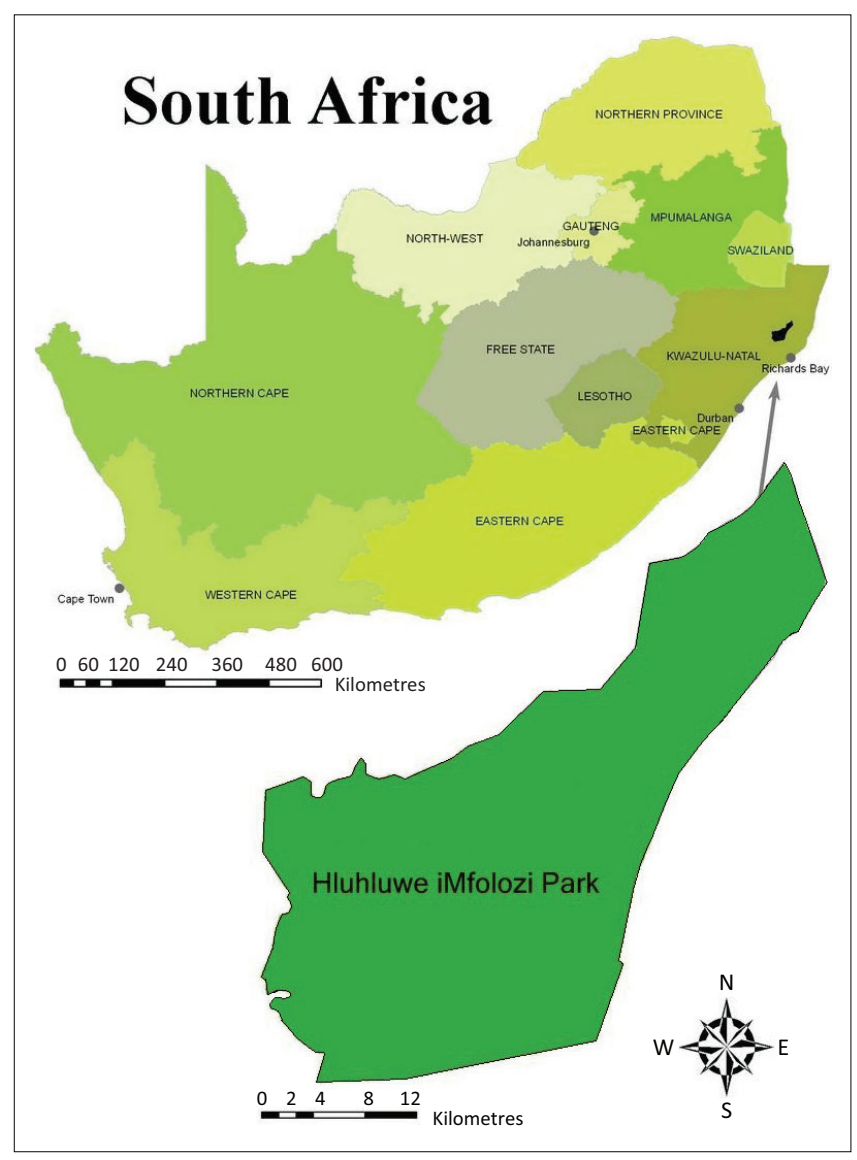

FIGURE 1: The location of Hluhluwe-iMfolozi Park in South Africa. 
(i.e. individual black rhinos that had not been ear-notched but were recognisable by other physical features, location or by association with notched animals) which had been sighted within the last three calendar years (Goodman 2013). The harvest rate $\left(\mathrm{h}_{t}\right)$ was calculated using the following formula (Goodman 2013):

$h_{t}=H_{t} / N_{t-1}$

[Eqn 1]

Where, $\mathrm{h}_{\mathrm{t}}=$ the harvest rate, $\mathrm{Ht}=$ the number of animals removed in year $t$ and $\mathrm{N}_{\mathrm{t}-1}$ = the population estimate in the preceding year (Goodman 2013).

\section{Population demographics}

We used population age structure information for the black rhino population at HiP from 1998 to the end of 2013. We used the detailed population status reports (i.e. demographics and status), compiled on the 31st of December each year to extract the relevant data.

\section{Age at sexual maturity}

Age at sexual maturity was determined as the age at which a female gave birth to her first calf. The mean ASM for the HiP population was determined using a sub-sample of 120 individual female black rhinos which were in the population in 1998 or in subsequent years even though they may have given birth to their first calf prior to 1998. These females had the most complete life-history records (i.e. their birth dates and the birth dates of their first and subsequent calves were known). Females which gave birth to their first calf before the end of 2013 were included.

\section{Inter-calving interval}

From the same sub-sample of 120 black rhino females, 79 had more than one calf prior to 31 December 2013 and these individuals were used to calculate ICIs. The mean ICI was calculated for each female with more than one calf, and ICIs for females from the same section (Masinda, Nqumeni etc.) were then combined to calculate the mean ICI for each section. The weighted mean ICI for the park was then calculated using the number of females from the five management sections, each of which had more than one calf prior to 31 December 2013.

\section{Fertility and fecundity rates}

Fertility rate $\left(\mathrm{FER}_{\mathrm{t}}\right)$, which is the number of calves born per year as a proportion of mature females (i.e. females aged $\geq 7$ years) in the population at the beginning of each year, was calculated as follows (Goodman 2013):

$\mathrm{FER}_{\mathrm{t}}=$ Births $_{\mathrm{t}} / \mathrm{Ad} \mathrm{F}_{\mathrm{t}-1}$

Where, Births $s_{t}$ is the number of births in the year under review and $A d F_{t-1}$ is the number of adult females (i.e. females aged $\geq 7$ years) in the preceding year (Goodman 2013). The fertility rate at HiP was calculated between 1998 and the end of 2013.

Fecundity rate $\left(\mathrm{FEC}_{\mathrm{t}}\right)$, which is the number of calves born in a year and still alive at the end of that year as a proportion of adult females (i.e. females $\geq 7$ years old) in the population at the beginning of each year, was calculated as follows:

$\mathrm{FEC}_{\mathrm{t}}=$ Surviving births $\mathrm{t}_{\mathrm{t}} \mathrm{Ad} \mathrm{F}_{\mathrm{t}-1}$

[Eqn 3]

Where, surviving births $s_{t}$ is the number of calves that survived in the year under review and $\mathrm{Ad} \mathrm{F}_{\mathrm{t}-1}$ is the number of adult females (i.e. females $\geq 7$ years old) in the preceding year (Goodman 2013). The fecundity rate at HiP was calculated from 2010 to 2013 when the relevant information was available.

\section{Mortality}

Mortality rate was calculated as the number of black rhinos that died per year divided by the number of animals alive at the beginning of that year (Sinclair, Fryxell \& Caughley 2006). The mortality rates were calculated from 2009 to 2013, a period when all mortalities were investigated and accurately documented.

\section{Statistical analysis}

Binomial proportions tests were used to test for any difference in the overall sex ratio of the black rhino calves born on HiP between 1998 and 2013 using R (R Development Core Team 2014). Data are presented as means \pm s.d. (unless stated otherwise), and the level of significance was set at $95 \%$ (i.e. $P=0.05$ ).

\section{Results \\ Population demographics}

Adult black rhinos (aged $>7$ years) comprised the greatest proportion of the HiP population in all years, and there were more females than males (Figures 2 and 3). The proportion of adult males in the population has stayed relatively stable (Figure 2), whereas the proportion of adult females has declined since 1998 (Figure 3). Juvenile (birth to 1 year) black rhinos made up the lowest proportion of the overall HiP population in all years (Figures 2 and 3). The proportion of sub-adult individuals ( $>1$ year but $<7$ years) fluctuated over time but remained relatively stable $( \pm 30 \%$ of the population) for the males (Figure 2). By contrast, the proportion of female sub-adults increased steadily from $\pm 24 \%$ in 1998 to $33.3 \%$ in 2013 (Figure 3).

There were no significant differences in the sex ratios of the black rhino calves born at HiP between 1998 and 2013, except in 2002 when significantly more female than male calves were born $\left(\chi^{2}=4 ; d f=1 ; P=0.045\right)$. In all years except 2002 , either only one calf of a particular sex was born or the ratio was 1:1. In 2002, the number of female calves born was double that of males. Between 1998 and 2003, the HiP black rhino population 


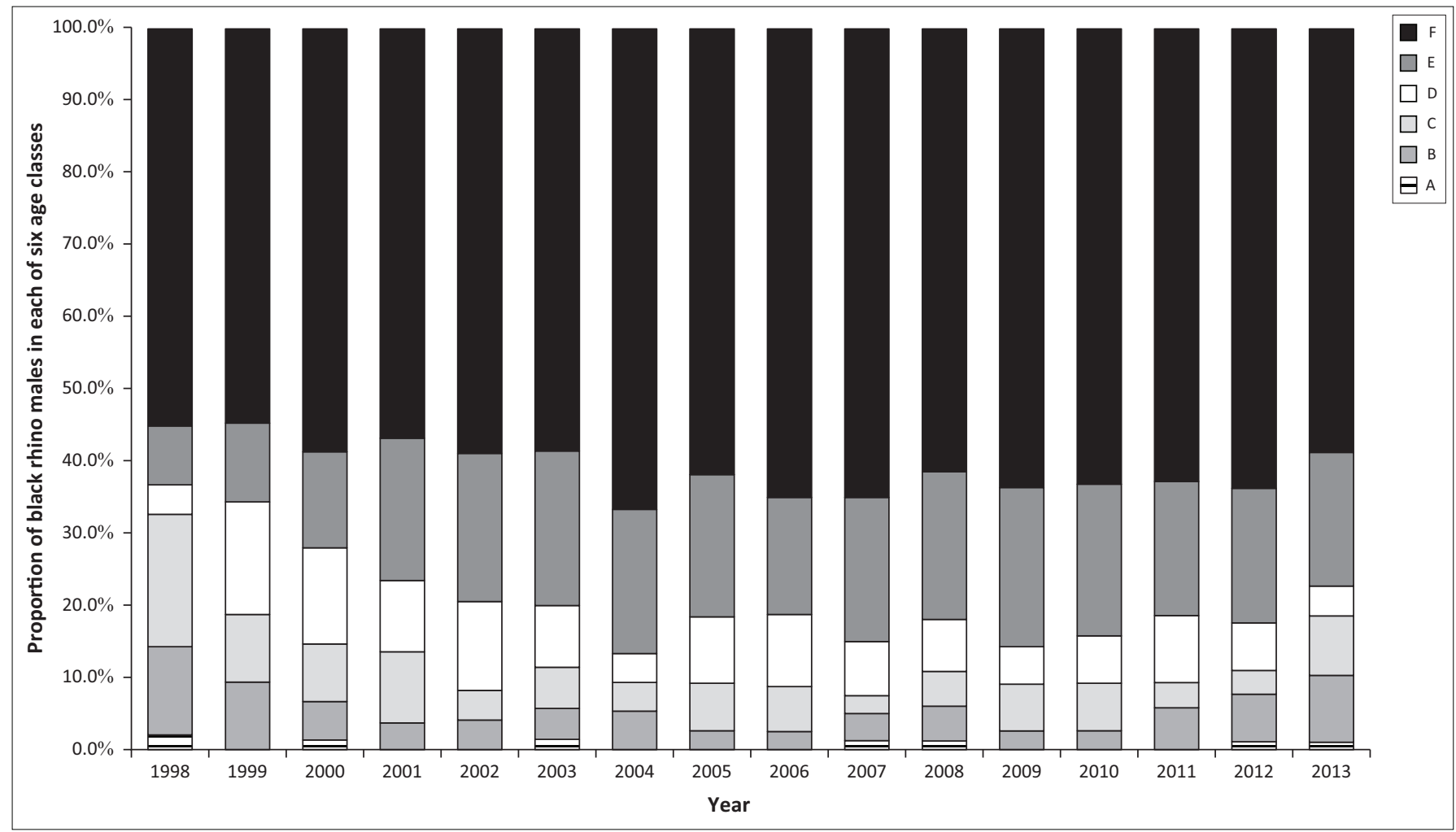

A, $<3$ months; $B$, 3 months -1 year; $C, 1-2$ years; $D, 2-3.5$ years; $E, 3.5-7$ years; $F,>7$ years.

FIGURE 2: Annual changes in the proportion of male black rhinos in each of the six age classes in Hluhluwe-iMfolozi Park on 31 December, annually from 1998 to 2013.

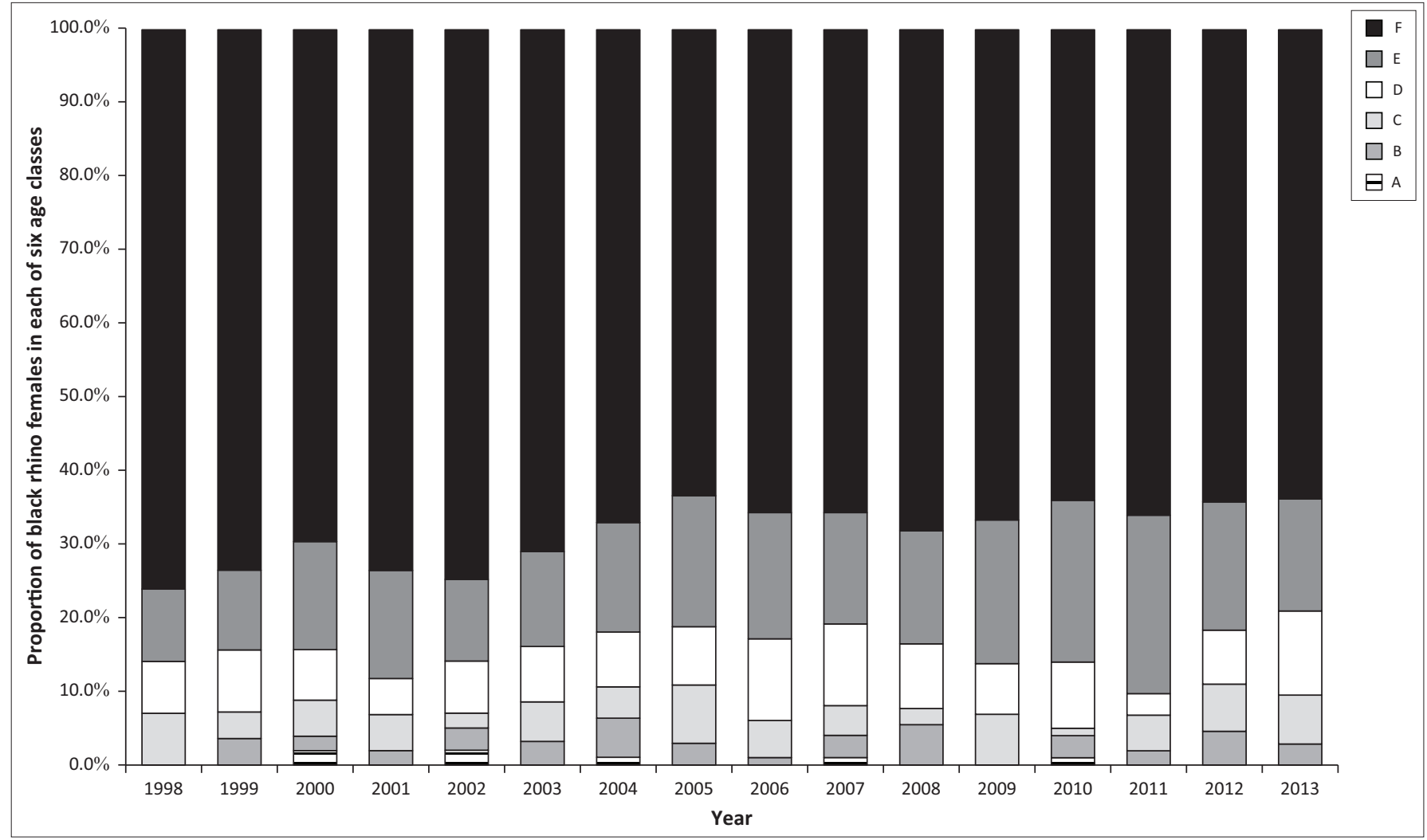

$A,<3$ months; B, 3 months -1 year; C, 1-2 years; D, 2-3.5 years; E, 3.5-7 years; $F,>7$ years.

FIGURE 3: Annual changes in the proportion of female black rhinos in each of the six age classes in Hluhluwe-iMfolozi Park on 31 December, annually from 1998 to 2013. 
had significantly more adult females than males (Table 1). Between 2004 and 2013, adult sex ratios were close to parity but remained slightly female biased except for 2005 and 2010 where significantly more females were present (Table 1 ).

\section{Age at sexual maturity}

The median ASM for the entire black rhino population at HiP was 11 years (132 months). The range in ASM was $4-23$ years $($ mean $=12$ years $/ 145 \pm 11$ months). Assuming a

TABLE 1: The number of adult ( $>7$ years old) male and female black rhinos and their sex ratio at Hluhluwe-iMfolozi Park between 1998 and 2013.

\begin{tabular}{lcccl}
\hline Year & Males & Females & Sex ratio & Statistics \\
\hline 1998 & 27 & 54 & $2: 1$ & $\chi^{2}=18 ; d f=1 ; P<0.0001$ \\
1999 & 35 & 61 & $1.7: 1$ & $\chi^{2}=14.08 ; d f=1 ; P<0.001$ \\
2000 & 44 & 71 & $1.7: 1$ & $\chi^{2}=12.68 ; d f=1 ; P<0.001$ \\
2001 & 46 & 75 & $1.6: 1$ & $\chi^{2}=13.90 ; d f=1 ; P<0.001$ \\
2002 & 43 & 74 & $1.7: 1$ & $\chi^{2}=16.43 ; d f=1 ; P<0.0001$ \\
2003 & 41 & 66 & $1.6: 1$ & $\chi^{2}=11.68 ; d f=1 ; P<0.001$ \\
2004 & 50 & 63 & $1.3: 1$ & N.S. \\
2005 & 47 & 64 & $1.4: 1$ & $\chi^{2}=5.21 ; d f=1 ; P<0.05$ \\
2006 & 52 & 65 & $1.3: 1$ & N.S. \\
2007 & 52 & 65 & $1.3: 1$ & N.S. \\
2008 & 51 & 62 & $1.2: 1$ & N.S. \\
2009 & 49 & 58 & $1.2: 1$ & N.S. \\
2010 & 48 & 64 & $1.3: 1$ & $\chi^{2}=4.57 ; d f=1 ; P<0.05$ \\
2011 & 54 & 68 & $1.3: 1$ & N.S. \\
2012 & 58 & 70 & $1.2: 1$ & N.S. \\
2013 & 57 & 67 & $1.2: 1$ & N.S. \\
\hline
\end{tabular}

Sex ratio is female to male. The results of the binomial proportions tests are also shown. N.S., not set. gestation length of 15 months (Goddard 1967), the mean age of first mating and conception was $130 \pm 11$ months (10 years). Median age of first mating and conception was 117 months (9 years and 9 months). The earliest mating (backdated from birth) recorded was of a female that was 2 years, 8 months (34 months) old and the oldest recorded mating was of a female aged 22 years, 5 months (269 months).

\section{Inter-calving interval, births per year and births per lifetime}

Of the 120 black rhino females for whom adequate records were available, 79 had more than one calf. This gave a subset of 190 ICIs (Figure 4). The weighted mean ICI was 3 years, 8 months ( $45 \pm 6$ months), and ICI ranged between 39 and 53 months across the five management sections of the park. The median ICI was 37 months - the shortest ICI was 1 year, 6 months (18 months) and the longest ICI was 9 years (108 months). When ICIs longer than 40 months were removed from the dataset (Hitchins \& Anderson 1983), 109 individual ICIs remained, and the calculation of the overall ICI for the HiP became 2 years, 5 months (29 \pm 6 months).

Using an ICI of 45 months, the births per year per female were 0.27 and when using an ICI of 29 , births per year increased to 0.41 per female. The oldest female recorded to give birth at HiP between 1998 and 2013 was aged 31 years and the mean age at first parturition was

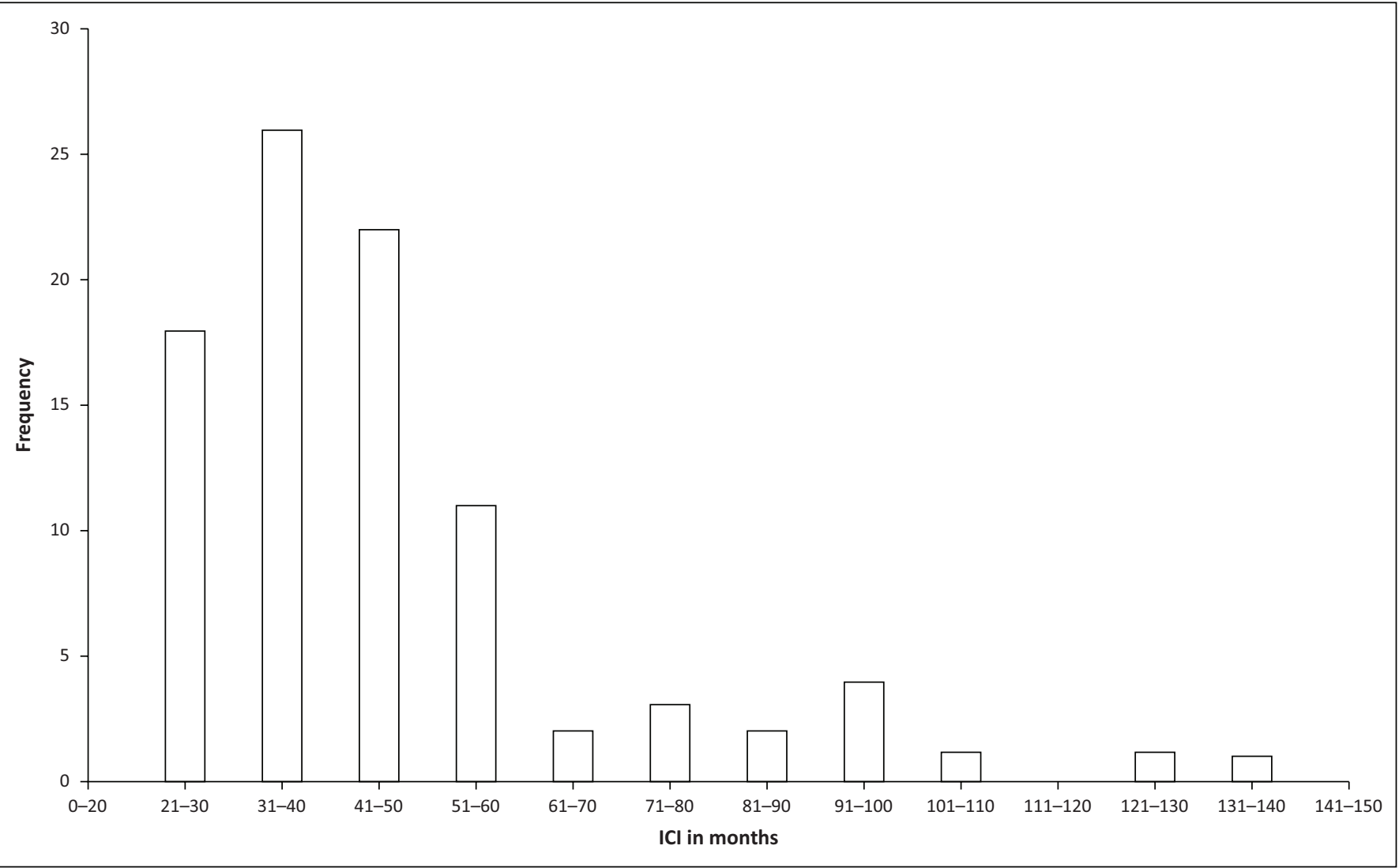

FIGURE 4: Histogram showing the frequency distribution of inter-calf intervals for the 79 black rhino females at Hluhluwe-iMfolozi Park, each of which had more than one calf prior to 31 December 2013. 
12.08 years ( $145 \pm 11$ months). Thus, if 31 years is assumed to be the age at which female black rhinos at HiP cease reproductive activity, the reproductive lifetime of the population is approximately 19 years. A female black rhino may therefore be expected to have between five and eight calves in her lifetime.

\section{Fertility and fecundity rates}

The fertility rate of black rhinos at HiP was lowest in 2006 and 2009 (0.17 for each year) and highest in 2000 (0.34). In the 16 years between 1998 and 2013, the fertility rate averaged 0.24 (Figure 5). The fecundity of the black rhino population at HiP was below 0.25 between 2010 and 2013. The lowest fecundity rate was 0.21 in 2010, whilst the highest rate was 0.24 in 2011 and 2013. The mean fecundity rate over the 4 years (2010-2013) was 0.23.

\section{Mortality}

The mortality rate of black rhinos at HiP was relatively low. The highest mortality rate was recorded in 2010 and 2013, when $0.07 \%$ of the population died. The total number of dead rhinos in 2013 was 14, only one calf died this year compared to other years where calf mortalities made up almost half of all mortalities. The remaining 13 deaths were of older individuals. The causes of death included fighting, natural death and poaching.

\section{Discussion}

\section{Population age structure}

In large, predator-free systems, the population growth of herbivorous mammals are most sensitive to adult survivorship (Gaillard et al. 1998, 2000). However, high temporal variation in juvenile survival typically drives variability in population growth rates (Gaillard et al. 1998, 2000) and is thus an important factor in determining fluctuations in the populations of large mammalian herbivores (Owen-Smith \& Mason 2005). In expanding mammalian populations, the proportion of juveniles and sub-adult animals will be relatively higher and the mean age of the population will be low (Coulson et al. 2004; OwenSmith 1988). Populations that are close to carrying capacity have a higher proportion of adult animals and a reduced juvenile survival and fecundity (Coulson et al. 2004). Stable populations are made up of about $60 \%-70 \%$ reproductively mature adults, whilst increasing populations have $45 \%-55 \%$ mature adults (Owen-Smith 1988). For example, an increasing black rhino population in the Great Fish River Nature Reserve (GFRNR), Eastern Cape, South Africa, comprised 20\% juveniles, 36\% sub-adults and 44\% adults (Fike 2011). By contrast, the Thomson's gazelle (Eudorcas thomsonii) population in the Serengeti, Tanzania, was shown to be in rapid decline when the population was made up of $12 \%$ juveniles and $70 \%$ adults (Borner et al. 1987). Owen-Smith

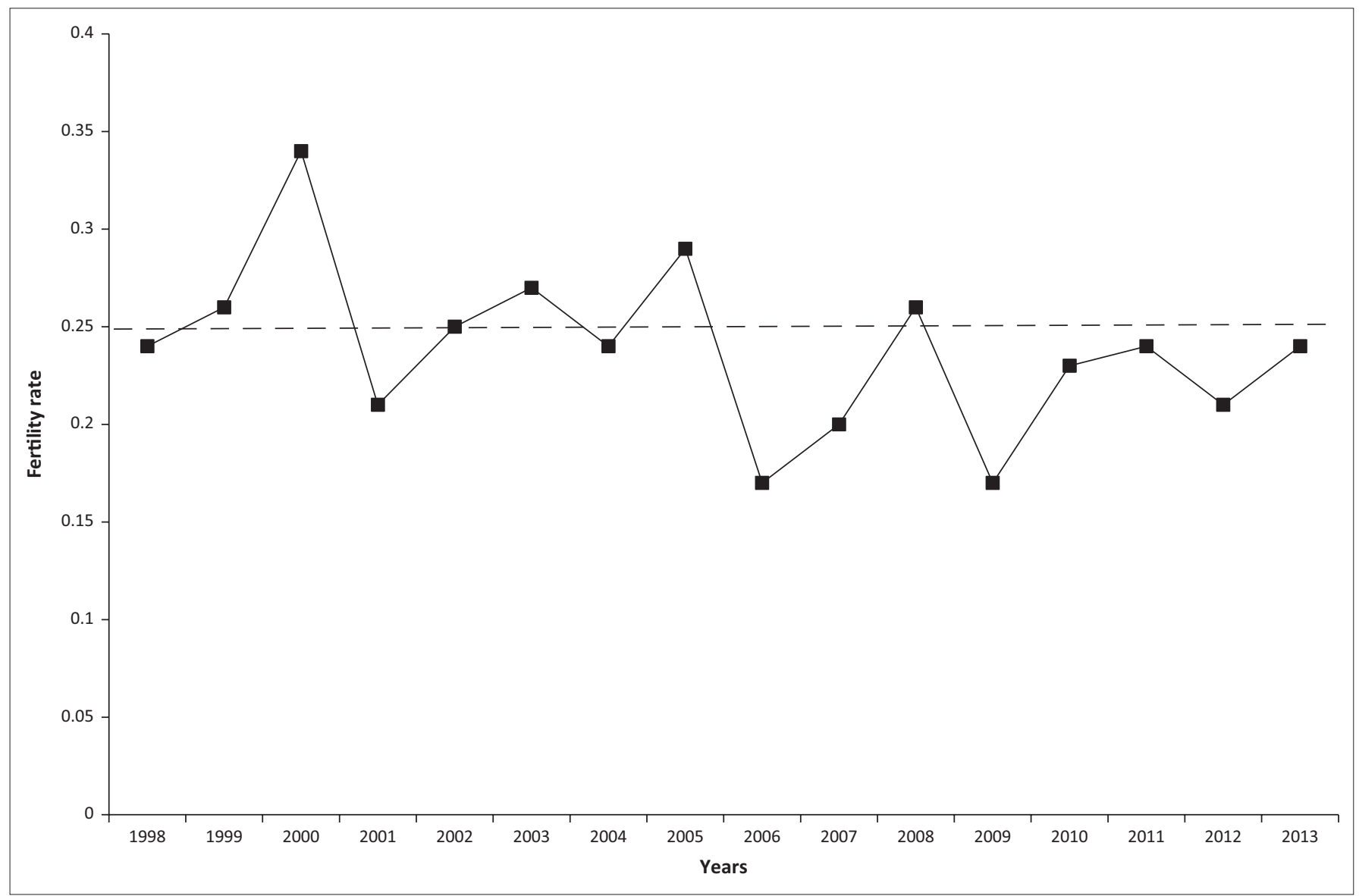

FIGURE 5: The mean fertility rate of the black rhino population at Hluhluwe-iMfolozi Park for 15 years, from 1998 to 2013 . The dashed line indicates the targeted fertility rate $(25 \%)$. 
(1988) demonstrated that an east African black rhino population which consisted of about $60 \%$ adults were categorised as stable. Our study shows that the current black rhino population at HiP consists of $63.2 \%$ adults, $25.5 \%$ subadults and $11.3 \%$ juveniles, suggesting that the population is stable (Owen-Smith 1988). However, the aim is to have a black rhino population which is growing and reproducing at a high rate. In order for this to occur, the proportion of juveniles and sub-adult animals needs to be higher than it currently is and the population should consist of between $45 \%$ and 55\% mature individuals (Coulson et al. 2004; OwenSmith 1988). An increase in the proportion of sub-adult females could potentially result in an increase in the fertility rates as more females could breed each year.

\section{Sex ratio}

Sex ratio is an essential factor influencing the growth rates and population dynamics of many large mammal populations (OkitaOuma et al. 2009; Weladji \& Laflamme-Mayer 2011). This is because it affects the reproductive potential of a population, which is the relative capacity of a species to reproduce under favourable conditions (Okita-Ouma et al. 2009; Weladji \& Laflamme-Mayer 2011). A population with a female skew, under favourable conditions, is expected to demonstrate high growth rates (Okita-Ouma et al. 2009). The favourable conditions will allow females to reach the body mass required for reproduction sooner and ASM will then be attained earlier (Gaillard et al. 2000).

Rainfall and range conditions at the time of conception have been found to influence conception rates and sex ratios in black rhinos (Berkeley \& Linklater 2010). More female black rhino offspring are born during years with below average rainfall and more males are conceived in the years with above average rainfall (Hrabar \& Du Toit 2005; Weladji \& LaflammeMayer 2011). The extrinsic modification hypothesis suggests that offspring sex can be influenced by the environmental conditions experienced by the mother (Weladji \& LaflammeMayer 2011). More male calves are born to dams that are gaining body condition during conception, compared to more female calves when dams are losing body condition at conception (Cameron \& Linklater 2007). An assessment and comparison of female body condition at the time of conception and calf sex was not possible during our study. However, research has shown that male foetuses are affected by poor maternal resources and weather experienced by the mother prior to conception and during mid to late gestation (Berkeley \& Linklater 2010; Gaillard et al. 2000; Weladji \& Laflamme-Mayer 2011). This is because females eating food with low nutrient levels have poor body condition and poor body condition in black rhinos affects the sex of the calf (Hrabar \& Du Toit 2005). Owen-Smith (1988) found that the flexibility in the time of conception in black rhinos could also allow females to selectively abort embryos of the less advantageous sex (males) during unfavourable conditions (Owen-Smith 1988). Previous periods with male-biased sex ratios in HiP were associated with conception that occurred during wetter seasons (Berkeley \& Linklater 2010).
In uMkhuze Game Reserve, which is $\pm 30 \mathrm{~km}$ north of HiP, a male-biased sex ratio was related to lower rainfall during pregnancy and a relatively high population size (Weladji \& Laflamme-Mayer 2011). An increase in population size could bring about increased competition for food resources and it would be advantageous to produce male calves that could potentially disperse away from their natal ranges (Weladji \& Laflamme-Mayer 2011). However, having more males in a fenced system could also be counter-productive because with limited space, male-male conflict (and hence mortality) is increased. The sex ratio for the black rhino population at the GFRNR in the Eastern Cape, South Africa, was 1.3 females per male (Fike 2011). This could be indicative of the lower than average rainfall experienced at GFRNR, Eastern Cape, South Africa, which resulted in more female calves being born (Hrabar \& Du Toit 2005). In HiP, the overall sex ratio was close to parity but the adult and sub-adult sex ratio was slightly female biased (1.2:1). A slightly female biased sex ratio for adults under favourable conditions should result in high growth rates and thus as increase in the population going forward (Okita-Ouma et al. 2009). Park managers are unable to manipulate the sex ratio of calves, but they could potentially manipulate the adult and sub-adult sex ratio through the removal of males.

\section{Age at sexual maturity}

The ASM in mammals differs between populations and even within the same species (Bronson 1989). The genetic makeup of each individual accounts for the differences in the ASM for females in the same population (Bronson 1989). Environmental factors such as food availability, ambient temperature and, to a lesser extent, humidity can influence reproductive development (Bronson 1989). These factors also influence ASM by influencing the rate of growth for each individual female (Bronson 1989). Evidence shows that underweight females and those on nutrient-poor diets may fail to ovulate (Hrabar \& Du Toit 2005). In addition, low rainfall reduces the quality and quantity of the food supply, negatively affecting the body condition of black rhino females (Hrabar \& Du Toit 2005).

A threshold mass must be attained by mammals before they can attain sexual maturity and thus reproduce (Gaillard et al. 2000). Black rhino populations in poor habitats may attain sexual maturity and thus reproduce much later than black rhino populations in better habitats (Gaillard et al. 2000). This is because poor nutrition in black rhino can lead to a delay in attaining the body weight required for reproduction (Patton, Campbell \& Parfet 2008).

At the GFRNR in the Eastern Cape, South Africa, the ASM ranged from 4 years, 10 months to 9 years and 3 months, with the mean ASM being 6 years and 8 months (Fike 2011). The ASM of the black rhino population in Ithala Game Reserve, KwaZulu-Natal, South Africa, was 6 years and 6 months (Greaver et al. 2013). A study similar to the current one yielded an ASM of between 5 years, 10 months and 6 years, 5 months (Hitchins \& Anderson 1983). Our data show that 
the ASM of black rhinos at HiP ranged between 4 and 23 years. The mean ASM was 12 years. The ASM for the current HiP population exceeds the 7 years and 5 months quoted in $\mathrm{du}$ Toit (2006) for poor performing populations and is almost double that of the $1983 \mathrm{HiP}$ estimate, and the GFRNR population. A number of potential reasons for this high ASM include, poor habitat (Gaillard et al. 2000), poor nutrition (Patton et al. 2008), changes in predator effects on juvenile black rhinos (Plotz \& Linklater 2009) and potentially negative social effects from annual removals. The black rhino females in the current HiP population could be conceiving much earlier but losing their calves before they are born due to poor body condition (Garnier, Holt \& Watson 2002; Patton et al. 2008). Removals may affect the social structure of populations. Such imbalance in the social structure may result in shifts in home ranges. Productivity may then be affected as individuals would expend more energy creating new home ranges rather than investing in reproductive activities (Patton et al. 2008). However, it is important to recognise that the calculation of ASM in our study is based on the determination of the first known calf of a female. Thus, it is possible that some calves may have died prior to them being recorded, and may therefore have been missed during monitoring, potentially inflating the ASM.

\section{Inter-calving interval}

The variation in the length of black rhino ICIs depends on the age of the female and the quality of food within her home range (Du Toit 2006). Under favourable conditions, black rhino females can produce successive calves every $2-3$ years (Du Toit 2006). During unfavourable conditions, the length of the ICI can be in excess of 3 years, 6 months (Du Toit 2006). ICIs are not restricted to yearly time increments because reproduction in black rhinos is asynchronous (Hrabar \& Du Toit 2005). Significantly, female megaherbivores can lengthen their ICI as an ecological response to food restrictions which occur when populations are close to carrying capacity (Owen-Smith 1988). Female black rhinos that are 28 years or older take longer to regain body condition after weaning calves and tend to have longer intervals between calves ( $\mathrm{Du}$ Toit 2006).

The ICIs for other South African black rhino populations range between 19 months and 7 years, 5 months (Fike 2011; Hall-Martin \& Penzhorn 1977; Hitchins \& Anderson 1983; Hrabar \& Du Toit 2005). In our study, the shortest ICI was 1 year, 6 months and the longest ICI was 8 years, 11 months. The mean ICI was 3 years, 9 months and this falls into the category of poor to very poor fecundity (Du Toit 2006). This poor fecundity could be due to unfavourable conditions in the park (Owen-Smith 1988). However, similar to the calculation of the ASM, any calves that were born but died before they were recorded could have inflated our estimates of ICI. Nevertheless, Freeman et al. (2014) suggested that black rhino ICIs can be extended in the presence of predators and where intra-specific competition is apparently high. Because of the annual live-harvesting of the HiP population, intra-specific competition is unlikely to be the major driver of
ICI extension. By contrast, predation of rhino calves may be an important factor increasing ICIs at HiP (see below and Gaillard et al. 2000).

\section{Births per year and lifetime productivity}

Reproduction in black rhinos in the wild may cease between 30 and 35 years (Garnier, Bruford \& Goosens 2001; Schenkel \& Schenkel-Hulliger 1969) or at the age of 40 (Owen-Smith 1988). With a mean ICI of 3 years, 8 months, the births per year for black rhino females at HiP were 0.3. This rate was less than the births per year of 0.4 found at GFRNR, Eastern Cape, South Africa, (Fike 2011) as a result of much longer ICIs at $\mathrm{HiP}$ or perhaps predation of calves, which were not detected through monitoring.

\section{Fertility rate}

Inter-calving interval and the gestation period determine the number of females that give birth each year (Owen-Smith 1988). ICI is affected by both density dependent and independent factors, and these factors also influence fertility rates (Hrabar \& Du Toit 2005). At high densities, the ICI increases and this causes a decline in the number of females that give birth each year (Hrabar \& Du Toit 2005). Under favourable conditions, ICI is at a minimum and this causes fertility rates to increase (Fike 2011; Hrabar \& Du Toit 2005). In the GFRNR, Eastern Cape, South Africa, the fertility rate was between $33 \%$ and $41 \%$ (Fike 2011). Pilanesberg National Park, North West, South Africa, had fertility rates of between $16 \%$ and $45 \%$ (Hrabar \& Du Toit 2005). At HiP, the highest fertility rates were reached in 2000 when $34 \%$ of adult females gave birth. The lowest fertility rates were observed in 2006 and 2009 when only $17 \%$ of adult females gave birth. The mean fertility rate for the current population was $24 \%$ which is just less than the $25 \%$ fertility rate target (Goodman 2013).

\section{Mortality}

Black rhino calf mortality rates within the first year after birth in South Africa and Namibia range between $8 \%$ and $14 \%$ (Du Toit 2006). Sub-adult mortalities are between $2 \%$ and $4 \%$, less than $2 \%$ in young and prime adults and $4 \%$ in much older adults (Du Toit 2006). Males have higher mortality rates than females because the main cause of death in males are wounds from fighting, whereas most females die of old age (Du Toit 2006). Mortality at HiP was relatively low and deaths were mostly of calves. The highest mortality in the 4 years between 2009 and 2012 was 7\% in 2010. Most calf mortalities occur within the first month of birth and are linked to maternal care in cases where predation on calves is not high (Gaillard et al. 2000). Maternal age, size and reproductive experience also have a strong influence on calf survival (Gaillard et al. 2000). Where predators are present, predation can account for about $50 \%$ of calf deaths. Maternal experience can lower calf vulnerability to predation (Gaillard et al. 2000). However, malnutrition is the main cause of early mortality and may cause females to abandon their young. Malnutrition also increases the juvenile's susceptibility to other sources of 
mortality such as disease because of a weak immune system (Gaillard et al. 2000). Calf mortalities made up most of the mortalities at HiP between 2009 and 2012. However, in 2013, most of the mortalities involved sub-adults and adults. It is possible that the better monitoring methods employed from 2009 onwards increased the chances of detecting calf births and mortalities than in previous years. It could also be a result of predation on the calves by lions (Panthera leo) and hyaenas (Crocuta crocuta), or malnutrition.

\section{Conclusion}

The black rhino population at HiP is an important donor population for the BRREP. This means that this population must perform well both genetically and demographically in order to continue contributing to the BRREP. The Rhino Management Group (RMG) targets set for black rhino subpopulations in the southern African region include a minimum of $5 \%$ growth rate per year and $25 \%$ fecundity (Goodman 2013). The current black rhino population at HiP did not quite attain the $25 \%$ fecundity target. However, the difference between the fecundity rate of the HiP population and the RMG target is small. Therefore, it can tentatively be concluded that the current HiP black rhino population is just meeting the minimum performance levels according to RMG standards. However, the delayed ASM and longer ICIs are a concern and need to be addressed to ensure the population reproduces at a higher rate.

The poor population performance of the HiP black rhinos could be a result of poor habitat quality, poor animal condition, females losing their first calves, predation of calves or a negative social effect of annual live-harvesting of the population. Annual rhino removals may be disrupting the social structure of the population, but we do not have any direct evidence to support this contention. It is unlikely that a lack of good-quality habitat is the main cause of the poor observed reproductive rates since reducing overall rhino densities through removals should theoretically reduce competition for food, resulting in improved reproductive rates. However, if the HiP black rhino population has (as our data point towards) already exceeded the estimated ecological carrying capacity, then habitat quality for black rhinos may, in fact, be declining in $\mathrm{HiP}$ as suggested by Reid et al. (2007). We agree that the ecological carrying capacity estimate itself is likely incorrect (Reid et al. 2007). If this estimate is incorrect, then it would likely explain the poor reproductive performance of the population. We therefore recommend that the accuracy of the ecological carrying capacity estimate be assessed as a matter of urgency to prevent the continued poor performance by the HiP black rhino population and that a moratorium be placed on the live-harvesting of individuals until the estimate has been refined.

\section{Acknowledgements}

We thank Geoff Clinning (Ezemvelo KZN Wildlife) for all his work in constructing the black rhino database for HiP, error- checking of historical data and for his assistance in providing data and comments. Heleen Druce assisted with the capture and error-checking of historical black rhino data. Bom Ndwandwe, numerous Ezemvelo KZN Wildlife field and scientific staff and students assisted with the field data collection over the years. We would like to thank the National Research Foundation and the Oppenheimer Memorial Trust for funding.

\section{Competing interests}

The authors declare that they have no financial or personal relationships that may have inappropriately influenced them in writing this article.

\section{Authors' contributions}

Z.N.N. was the project leader. Z.N.N., D.M.P. and D.J.D. were responsible for the project design. Z.N.N. collected some of the field data and analysed these data with the assistance of D.M.P. and D.J.D. All authors were involved in the writing of the article and the interpretation of the results.

\section{References}

Berkeley, E.V. \& Linklater, W.L., 2010, 'Annual and seasonal rainfall may influence progeny sex ratio in the black rhinoceros', South African Journal of Wildlife Research 40, 53-57. https://doi.org/10.3957/056.040.0102

Borner, M., Fitzgibbon, C.D., Borner, M., Caro T.M., Lindsay, W.K., Collins, D.A. et al. 1987, 'The decline of the Serengeti Thomson's gazelle population', Oecologia 73, 32-40. https://doi.org/10.1007/BF00376974

Bronson, F.H., 1989, Mammalian reproductive biology, The University of Chicago Press, Chicago, IL.

Brooks, M. \& Adcock, K., 1997, Conservation plan for the black rhinoceros Diceros bicornis in South Africa, Report, The Rhino Management Group, Pietermaritzburg.

Brooks, S., 2000, 'Re-reading the Hluhluwe-Umfolozi game reserve: Constructions of a natural space', Transformation 44, 63-79.

Cameron, E.Z. \& Linklater, W.L., 2007, 'Extreme sex ratio variation in relation to change in condition around conception', Biology Letters 3, 395-397. https://doi. org/10.1098/rsbl.2007.0089

Clinning, G., Druce, D., Robertson, D., Bird, J. \& Nxele, B., 2009, Black rhino in Hluhluwe-iMfolozi Park: Historical records, status of current population and monitoring and future management recommendations, Report, Ezemvelo KZN Wildlife, Pietermaritzburg.

Conway, A.J. \& Goodman, P.S., 2013, Strategy for the management of black rhinocerous (Diceros bicornis minor) in KwaZulu-Natal, Report, Ezemvelo KZN rhinocerous (Diceros bicorn
Wildlife, Pietermaritzburg.

Coulson, T., Guiness, F., Pemberton, J. \& Clutton-Brock, T.H., 2004, 'The demographic consequences of releasing a population of red deer from culling', Ecology 85, 411-422. https://doi.org/10.1890/03-0009

Cowling, R.M., Richardson, D.M. \& Pierce, S.M., 1997, Vegetation of southern Africa, Cambridge University Press, Cape Town

Du Toit, R., 2006, Guidelines for implementing SADC Rhino conservation strategies, Report, SADC Regional Programme for Rhino Conservation, Pretoria.

Emslie, R.H. \& Brooks, M., 1999, African Rhino: Status survey and conservation action plan, IUCN/SSC African Rhino Specialist Group, Gland.

Ezemvelo KZN Wildlife, 2011, Integrated management plan: Hluhluwe-iMfolozi Park, South Africa, Report, Ezemvelo KZN Wildlife, Pietermaritzburg.

Fike, B., 2011, 'The demography and population dynamics of a re-introduced black rhinoceros population on the Great Fish River Reserve, Eastern Cape Province', MSc thesis, Department of Zoology \& Entomology, Rhodes University.

Fowler, C.W., 1981, 'Density dependence as related to life history strategy', Ecolological Society of America 62, 602-610. https://doi.org/10.2307/1937727

Freeman, E.W., Meyer, J.M., Bird, J., Adendorff, J., Schulte, B.A. \& Santymire, R.M., 2014, 'Impacts of environmental pressures on the reproductive physiology of subpopulations of black rhinoceros (Diceros bicornis bicornis) in Addo Elephant National Park, South Africa', Conservation Physiology 2, cot034.

Gaillard, J.-M., Festa-Bianchet, M. \& Yoccoz, N.G., 1998, 'Population dynamics of large herbivores: Variable recruitment with constant adult survival', Trends in Ecology and Evolution 13, 58-63. https://doi.org/10.1016/S0169-5347(97)01237-8

Gaillard, J.-M., Festa-Bianchet, M., Yoccoz, N.G., Loison, A. \& Toigo, C., 2000, 'Temporal variation in fitness components and dynamics of large herbivores', Annual Review of Ecology Systematics 31, 367-393. https://doi.org/10.1146/annurev.ecolsys.31.1.367 
Garnier, J.N., Bruford, M.W. \& Goosens, B., 2001, 'Mating systems and reproductive skew in the black rhino', Molecular Ecology 10, 2031-2041. https://doi. org/10.1046/j.0962-1083.2001.01338.x

Garnier, J.N., Holt, W.V. \& Watson, P.F., 2002, 'Non-onvasive assessment of oestrus cycles and evaluation of reproductive seasonality in the female wild black rhinoceros (Diceros bicornis minor)', Reproduction 123, 877-889. https://doi org/10.1530/rep.0.1230877

Goddard, J., 1967, 'Home range, behaviour and recruitment rates of two black rhinoceros populations', East African Wildlife Journal 5 , 133-150. https://doi. org/10.1111/j.1365-2028.1967.tb00768.x

Goodman, P.S., 2013, Ezemvelo KZN Wildlife Monitoring Plan: Black rhinoceros (Diceros bicornis minor), Unpublished report, Ezemvelo KZN Wildlife, Pietermaritzburg, South Africa.

Greaver, C., Ferreira, S. \& Slotow, R., 2013, 'Density-dependent regulation of the critically endangered black rhinoceros population in Ithala Game Reserve, South Africa', Austral Ecology 39, 1-11.

Hall-Martin, A.J. \& Penzhoen, B.L., 1977, 'Behaviour and recruitment of translocated black rhinoceros Diceros bicornis', Koedoe 20, 147-162. https://doi.org/10.4102/ koedoe.v20i1.941

Hitchins, P.M. \& Anderson, J.L., 1983, 'Reproduction, population characteristics and management of the black rhinoceros Diceros bicornis minor in the Hluhluwe/ Corridor/Umfolozi Game Reserve Complex', South African Journal of Wildlife Research 13, 78-85.

Hrabar, H. \& Du Toit, J.T., 2005, 'Dynamics of a protected black rhino (Diceros bicornis) population: Pilanesberg National Park South Africa', Animal Conservation 8, 259267. https://doi.org/10.1017/S1367943005002234

International Union for Conservation of Nature (IUCN), 2012, IUCN red list of threatened species (ver. 2012.2), viewed 17 October 2012, from http://www.iucnredlist.org

Okita-Ouma, B., Amin, R., Van Langevelde, F. \& Leader-Willians, N., 2009, 'Density dependence and population dynamics of black rhinos (Diceros bicornis michaeli) in Kenya's rhino sanctuaries', African Journal of Ecology 3, 791-799. https://doi. org/10.1111/j.1365-2028.2009.01179.x
Owen-Smith, R.N., 1988, Megaherbivores: The influence of very large body size on ecology, Cambridge University Press, Cape Town.

Owen-Smith, R.N. \& Mason, D.R., 2005, 'Comparative changes in adult vs. juvenile survival affecting population trends of African ungulates', Journal of Animal Ecology 74, 762-773. https://doi.org/10.1111/j.1365-2656.2005. 00973. $\mathrm{x}$

Patton, F. Campbell, P. \& Parfet, E., 2008, 'Biological management of the high density black rhino population in Solio Game Reserve, central Kenya', Pachyderm 44, 72-79.

Plotz, R.D. \& Linklater, W.L, 2009, 'Black rhinoceros (Diceros bicornis) calf succumbs after lion predation attempt: Implications for conservation management', African Zoology 44, 283-287. https://doi.org/10.3377/004.044.0216

$\mathrm{R}$ Development Core Team, 2014, R: A language and environment for statistical computing, R Foundation for Statistical Computing, Vienna.

Reid, C., Slotow, R., Howison, O. \& Balfour, D., 2007, 'Habitat changes reduce the carrying capacity of Hluhluwe-Umfolozi Park, South Africa, for critically endangered black rhinoceros Diceros bicornis', Oryx 41, 247-254. https://doi. org/10.1017/S0030605307001780

Schenkel, R. \& Schenkel-Hulliger, L., 1969, Ecology and behaviour of the black rhinoceros (Diceros bicornis L.): A field study, Paul Parey, Hamburg.

Sinclair, A.R.E., Fryxell, J.M. \& Caughley, G., 2006, Wildlife ecology, conservation and management, Blackwell, Oxford.

Weladji, R. B. \& Laflamme-Mayer, K., 2011, 'Influence of environmental conditions on sex allocation in the black rhinoceros population of Mkhuze Game Reserve, South Africa', African Journal of Ecology 49, 471-480. https://doi.org/10.1111/j.13652028.2011.01280.x

WWF, 2012, Black Rhino Range Expansion Programme, viewed 27 July 2012, from www.wwf.org.za.what_we_do/species/black/rhino/ 